\title{
What to expect, and how to improve online discussion forums: the instructors' perspective
}

\author{
Dhanielly P. R. de Lima1* (D), Marco A. Gerosa², Tayana U. Conte ${ }^{1}$ and José Francisco de M. Netto'
}

\begin{abstract}
Online discussion forums are asynchronous communication tools that are widely used in Learning Management Systems. However, instructors and students face various difficulties, and instructors lack a guide on what strategies they can use to achieve a more participatory forum environment. This work aims to identify benefits and difficulties of using online discussion forums from the instructors' point of view, and to provide a list of strategies and improvements that can mitigate the challenges and lead to a more participatory forum. We used coding procedures to analyze data collected through semi-structured interviews. The results of our exploratory analysis are relevant to the distance learning community and can inform instructors, developers, and researchers to help them improve the quality of mediation and use of forums.
\end{abstract}

Keywords: Empirical study, Online discussion forum, LMS, Difficulties, Barriers, Hurdles, Benefits, Strategies, Instructors, Mediators

\section{Introduction}

Since interaction is a key component in the quality of online learning [1], Learning Management Systems and MOOCs frequently adopt asynchronous online discussion forums to foster interaction [2-4]. Forums enable instructors to understand and intervene in learning activities [5, 6], and students have time to think and formulate answers. Individuals collaboratively build knowledge while collaborating in an asynchronous online environment [7]. Therefore, a well-coordinated educational forum is a valuable tool to promote reflection on learning, share information and perspectives, and connect students [8].

However, forums can experience both periods of inactivity and intermittent flurries of messages [9]. Without adequate feedback, only low levels of cognitive engagement occur, and students may feel isolated [10]. Feeling isolated can result in limited participation or lack of depth and quality of the discussion [11].

While prior literature focuses on specific improvements to online discussion forums, or include a list of benefits, difficulties, and strategies alongside their primary results

\footnotetext{
* Correspondence: dhanielly@icomp.ufam.edu.br

${ }^{1}$ Federal University of Amazonas - UFAM, Manaus, Brazil

Full list of author information is available at the end of the article
}

[11-20], no study has primarily focused on identifying benefits, difficulties, strategies, and possible improvements from the instructors' point of view. Understanding the perceptions of instructors is important, since they work closely with a variety of students and have a comprehensive view of the tool, which they use in multiple contexts.

Therefore, the goal of this work is to identify and categorize benefits, difficulties, strategies, and improvements for online discussion forums from the point of view of instructors who are experienced in computing technology and/or distance learning via Internet. Cataloging benefits and difficulties is useful for novice instructors to know what to expect or to aim when mediating educational forums, while investigating strategies and improvements may help instructors and tool designers to alleviate the difficulties and enhance the tool. To reach this goal, we defined the following research questions:

RQ1. What benefits of using educational discussion forums are perceived by instructors?

RQ2. What difficulties in using educational discussion forums are perceived by instructors?

RQ3. What strategies do instructors use to mediate discussion forums? 


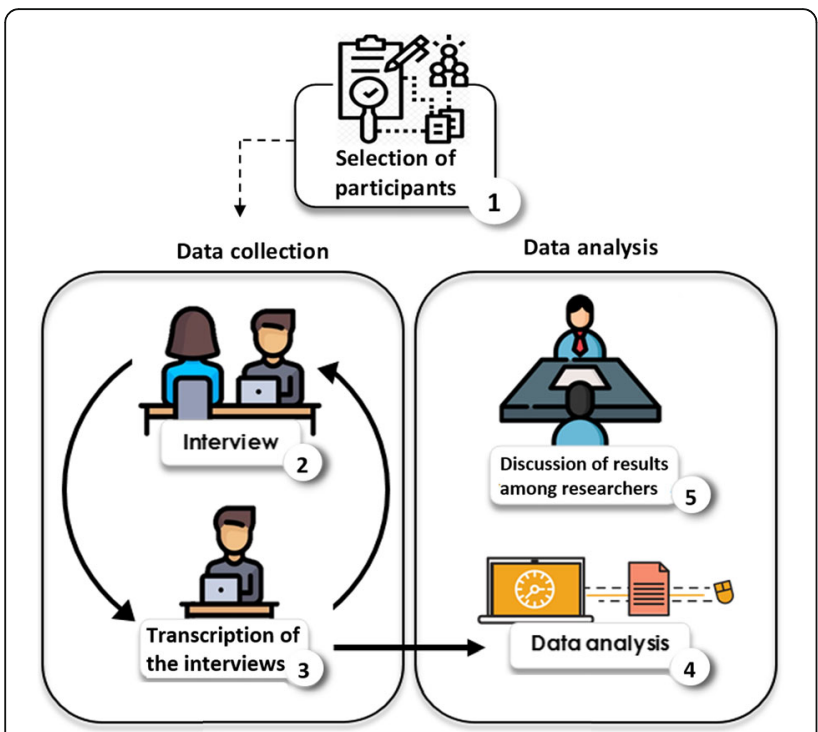

Fig. 1 Study overview. The figure presents the steps performed in the empirical study

RQ4. What improvements can be implemented in discussion forums according to the instructors?

To answer these research questions, we conducted an exploratory qualitative study with instructors who work in distance learning. We collected data through semi-structured interviews and analyzed the data using Grounded-Theory procedures, cataloging and discussing a set of benefits, difficulties, strategies, and improvements.

\section{Method}

We conducted semi-structured interviews with 12 instructors who teach distance learning classes that use discussion forums. For data analysis, we used procedures of Grounded Theory [21]. Figure 1 presents the steps performed in our exploratory empirical study, which are detailed in the following subsections.

\subsection{Selection of participants}

To carry out the interviews, we invited instructors from different institutions who teach distance learning classes that use discussion forums and who have experience with distance learning and/or computing technology. In total, 12 instructors participated in the interview. All participants signed the Term of Free and Informed Consent. ${ }^{1}$ The instructors who participated in the interview and were considered "experienced instructors" have at

\footnotetext{
${ }^{1}$ Informed Consent is available at https://docs.google.com/document/ d/1DkCeqfLXcTmCeFi7-1_65JcijXYk1-o9JdD9VA-trcc/edit?usp= sharing
}

Table 1 Experience in distance learning

\begin{tabular}{lll}
\hline Experience & Count & Percentage \\
\hline Between 1 years and 2 year & 3 & $25 \%$ \\
Between 3 years and 4 years & 3 & $25 \%$ \\
More than 5 years & 6 & $50 \%$ \\
\hline
\end{tabular}

least five years of experience with distance learning (Table 1).

Among the instructors who participated, two have more than ten years of experience, as shown in Table 2. Their reports revealed needs that have been faced for years and have not been addressed. For example, I1 has more than 10 years of experience and has already worked in distance learning courses as Coordinator, Instructor, and Monitor. In addition, I1 reported in the interview that in his undergraduate he participated as a student in distance learning courses.

The instructors of the Institutions " $\mathrm{A}$ " and " $\mathrm{C}$ " use the forum to promote the discussion of the topics covered in the course and to promote collaboration among students. Instructors from institution B usually use the forum to ask questions and to provide warnings and reminders to students. In addition to using the forum for questions, I3 also uses it to discuss the subjects taught in the course.

Table 3 presents information about the institutions and the LMS used.

Institution "A" provides periodic training for its instructors. In institutions $B$ and $C$, the courses are semipresential and the use of the forum is not mandatory, but the instructors use the forum tool to discuss the subjects that are taught in the virtual environment.

\subsection{Data collection}

The questions of the interview script were organized into three categories: instructor profile, mediation, and perceptions about discussion forums. ${ }^{2}$ The categories aimed to help and direct the interviewer; however, the interviews did not necessarily follow the order of the categories. Table 4 presents the questions that were used as guide for the profile category.

Table 5 presents questions related to practices of mediation in online forums focused on the structure of the forum, how mediation occurs, how the forum is used, etc. The questions related to the instructors' perceptions about the forum tool (Table 6) directly asked about difficulties, benefits, strategies, and improvements.

We employed two cycles of interviews, transcriptions, and analysis. Two researchers performed the transcriptions, as suggested by Runeson et al. [22], contributing

\footnotetext{
${ }^{2}$ Interview script is available at https://docs.google.com/document/d/1 NtaWEgaIPd739a8kfNj636Cq4358eLWOdxP96F5LIeE/edit?usp= sharing
} 
Table 2 Profile of the interviewees

\begin{tabular}{|c|c|c|c|c|c|c|c|c|}
\hline \multirow[t]{2}{*}{ ID } & \multirow[t]{2}{*}{$G N^{b}$} & \multirow[t]{2}{*}{ Course } & \multicolumn{3}{|c|}{ Main Occupation ${ }^{\mathrm{a}}$} & \multirow[t]{2}{*}{$\operatorname{lnst}^{\mathrm{e}}$} & \multirow{2}{*}{$\begin{array}{l}\text { Interview } \\
\text { Time }\end{array}$} & \multirow{2}{*}{$\begin{array}{l}\text { New } \\
\text { codes }\end{array}$} \\
\hline & & & $\overline{\text { Coord }^{c}}$ & $\operatorname{lnstr}^{d}$ & $\overline{\text { Tutor }}$ & & & \\
\hline 11 & M & $\mathrm{Biol}^{f}$ & 10 & 10 & 4 & A & $36 \mathrm{~m} 33 \mathrm{~s}$ & 34 \\
\hline 12 & $\mathrm{~F}$ & $\operatorname{lnfor}^{9}$ & & 1 & & B & $10 \mathrm{~m} 35 \mathrm{~s}$ & 11 \\
\hline 13 & M & Infor & & 3 & & B & $14 \mathrm{~m} 45 \mathrm{~s}$ & 20 \\
\hline 14 & M & Infor & & 3 & & C & $22 \mathrm{~m} 39 \mathrm{~s}$ & 27 \\
\hline 15 & $\mathrm{~F}$ & Infor & 2 & 2 & 1 & C & $26 \mathrm{~m} 29 \mathrm{~s}$ & 23 \\
\hline 16 & M & Infor & & 1 & 1 & C & $17 \mathrm{~m} 30 \mathrm{~s}$ & 17 \\
\hline 17 & M & Infor & & 17 & & B & $22 \mathrm{~m}$ & 15 \\
\hline 18 & $\mathrm{~F}$ & Infor & 3 & 3 & & A & $16 \mathrm{~m} 50 \mathrm{~s}$ & 12 \\
\hline 19 & M & Infor & & 1 & & B & $10 \mathrm{~m}$ & 5 \\
\hline 110 & $\mathrm{~F}$ & Infor & & 3 & & B & $18 \mathrm{~m} 41 \mathrm{~s}$ & 7 \\
\hline 111 & $\mathrm{~F}$ & Ped $^{\text {h }}$ & 6 & 4 & & A & $30 \mathrm{~m} 24 \mathrm{~s}$ & 3 \\
\hline 112 & $\mathrm{~F}$ & Lang $^{\mathrm{i}}$ & 4 & 1 & 3 & A & $19 \mathrm{~m} 20 \mathrm{~s}$ & 5 \\
\hline
\end{tabular}

${ }^{a}$ Main Occupation - time in years; ${ }^{\mathrm{b}} \mathrm{GN}$ - Gender; ${ }^{\mathrm{c}}$ Coord - Coordinator; ${ }^{\mathrm{d}}$ Instr Instructor; ${ }^{\mathrm{e}}$ Inst - Institution; ${ }^{\mathrm{f}} \mathrm{Biol}$ - Biology; ${ }^{\mathrm{I}}$ Infor - Informatics; ${ }^{\mathrm{h}} \mathrm{Ped}$

Pedagogy; 'Lang - Portuguese Language

to a better understanding of the collected data. The interview transcriptions were imported into the Atlas. $\mathrm{ti}^{3}$ software. All the interviews' transcriptions and analysis were carried out in Portuguese, the native language of the authors and interviewees.

\subsection{Data analysis}

We transcribed the interviews and analyzed them using procedures of the Grounded Theory method. According to Glaser and Strauss [21], Grounded Theory is a scientific method that uses a set of systematic procedures of data collection and analysis to generate, elaborate, and validate substantive theories [23]. The emphasis of Grounded Theory is learning from the data rather than from an existing theoretical view [24].

According to Strauss and Corbin [25], Grounded Theory is based on the idea of coding to analyze the data. The coding process can be divided into three phases: open, axial, and selective coding. Open coding involves breaking, analyzing, comparing, conceptualizing, and categorizing the collected data and aims to give sense to it [25]. Figure 2a illustrates the open coding.

After obtaining and transcribing the interviews, the investigator carefully examines the data and cuts out the units of analysis. Each unit of analysis is named with a word or sentence expressing its meaning for the investigator. The goal of open coding is to generate and validate properties and categories using constant comparisons [24], which help the researchers to define a set of conditions to reach a category. According to Glaser [26], the researchers must use the theoretical sensitivity to give meaning to the data and be able to separate what is relevant for the research.

\footnotetext{
${ }^{3}$ Atlas.ti software is available at http://atlasti.com/
}

Table 3 Profile of the institutions

\begin{tabular}{lllll}
\hline Institution & Type & LMS & Forum & $\begin{array}{l}\text { Teaching } \\
\text { modality }\end{array}$ \\
\hline A & Public & Moodle & Mandatory & $100 \%$ online \\
B & Public & $\begin{array}{l}\text { Custom Moodle } \\
\text { and Edmodo }\end{array}$ & Not mandatory & semi-presential \\
C & Public & Custom Moodle & Not mandatory & semi-presential \\
\hline
\end{tabular}

With the defined categories, we begin the axial coding phase, as depicted in Fig. 2b, which is a Chart Scheme of the associations between the codes. The figure presents the "Structural Difficulty" category and its subcategories.

\section{Results}

From the analysis of the interviews, we identified: a) benefits perceived by instructors, b) difficulties faced in discussion forums, c) strategies used by instructors, and d) improvements that can be made to the forum tool. These results are discussed in the following subsections. In addition, to make it easier to understand the results, we have included the Chart Scheme of the associations between the codes: benefits (Additional file 1), difficulties (Additional file 2) and improvements (Additional file 3) and the mapping between benefits, difficulties, strategies and improvements (Additional file 4).

\subsection{RQ1. What benefits of using educational discussion forums are perceived by instructors?}

We identified 4 categories of benefits from the instructors' perspective, as presented in Fig. 3.

The depth of the discussion - ID B1 (mentioned by instructors I1, I3, I7, I11) was reported as beneficial since forum participants have time to elaborate their answers

Table 4 Questions related to instructor profile

\begin{tabular}{ll}
\hline ID & Questions addressed to the Profile of the instructor interviewed \\
\hline 1 & $\begin{array}{l}\text { At present what is your main occupation? (Exemplify: if you } \\
\text { are an instructor, tutor, or environment manager). }\end{array}$ \\
3 & How long have you been working in distance education? \\
How much time do you spend on distance learning courses? \\
() Less than $2 \mathrm{~h} /$ week \\
() From 2 to $4 \mathrm{~h} /$ week \\
() From 5 to $7 \mathrm{~h} /$ week \\
() From 8 to $10 \mathrm{~h} /$ week \\
() More than $10 \mathrm{~h} /$ week \\
In your opinion, what is the role of the instructor and the \\
role of the tutor in distance learning? \\
What is the expected profile for distance education instructors? \\
(Exemplify: what techniques they should have, what tools they \\
need to know, commitment, skills, types of problems they should \\
know how to solve).
\end{tabular}


Table 5 Mediation category

\begin{tabular}{ll}
\hline ID $\quad$ Questions for Mediation \\
\hline $1 \quad$ Do you use the forum in your discipline? (How does he use \\
the forum and in which cases does he not use it?). \\
$3 \quad$ Can you use the forum as a communication strategy? \\
Can you understand the structure of the forum responses? \\
Do you find it difficult to keep up with the discussion? \\
What would the mediation structure be like? (Imagine you \\
have to help an instructor who has never worked with \\
Distance Education courses. Step-by-step how you would \\
structure the course to help the instructor promote \\
interaction and exchange of student knowledge.) \\
Do you usually intervene in the conversations taking place in \\
the forum? In what situations do you take part in the forum? \\
Do you remember an instance in the discussion forum that \\
interfered with communication and interaction? \\
Do you as an instructor motivate students to cooperate in \\
the forum? \\
$\quad$ Can you keep track of student interactions in the forum? \\
(Can you follow the forum in terms of the time that the \\
interactions take place and the depth of the conversations?).
\end{tabular}

and reflect on what they want to post: "The conversations tend to be deeper, because you see that message, reflect on it, and get a chance to better work on your idea" I3.

Collaboration - ID B2 (mentioned by instructors I2, I4, I5, I6, I8, I11, I12) was reported by instructors as a benefit, mainly due to the communication and

Table 6 Perception category

\begin{tabular}{ll}
\hline ID & Questions for Perception \\
\hline 1 & $\begin{array}{l}\text { Is it possible to see through the forum the cooperation between } \\
\text { students? (Do students cooperate through the forum?) } \\
\text { Do you think that students see the discussion forum as a } \\
\text { communication tool or only as an evaluation tool? } \\
\text { In the forum, the agent that predominates in the debate is: } \\
\text { () Instructor () Tutor } \\
\text { () Student () Both. Which are? } \\
\text { In your opinion, what elements of collaboration predominate } \\
\text { in the forum: } \\
\text { () Communication () Cooperation } \\
\text { () Coordination by the instructor } \\
\text { () More than one. Which are? } \\
\text { What are the difficulties you perceive in the students when } \\
\text { they are using the forum? (Can students understand the } \\
\text { structure of the answers in the forums?) } \\
\text { What are the difficulties encountered by you as an } \\
\text { instructor in the discussion forum? } \\
\text { What are the positive points of the discussion forum? } \\
9\end{array} \quad \begin{array}{l}\text { During the time you worked with Distance Education courses, } \\
\text { have you ever been surprised by the forum? } \\
\text { What do you think could be done in the forum to } \\
\text { potentialize it? (Suggestions for the forum). }\end{array}$ \\
\hline
\end{tabular}

cooperation perspectives. According to I5: "The forum is very important as a collaborative activity tool."

Information record, ID B3 (mentioned by instructors I1, I7, I9, I10) was also appreciated by instructors. According to I1: "With the logs, everything stays on the platform. You know who is interacting with whom, which individuals are not participating, or disagreeing, and whether the participations are taking place in the spaces that should happen."

Finally, information visualization, ID B4 (mentioned by instructors I1, I2, I4, I5, I8, I11, I12) enables instructors to visualize student interactions and polemic topics, as explained by I4: "You can see what the students are debating, what are the most discussed subjects, identify who is participating and who is not interacting." The forum enables a in-depth discussion and can be used as a communication and monitoring tool for learning.

\subsection{RQ2. What difficulties in using educational discussion forums are perceived by instructors?}

We identified 19 types of difficulties from the interviews. These difficulties were grouped into three categories: forum structure, motivation, and accompaniment, as can be seen in Table 7 .

The difficulties with the highest occurrences are D1, D6, D7, D13, D14, and D17, which involve difficulties related to the hierarchical structure of the forum. D1, Difficulties in following the forum refer to the difficulties that instructors and students face to follow the discussion due to the high number of posts that occur in the tool. D6 and D7, Difficulties related to the structure of the forum, are the difficulties that involve the forum's interface. D13, Difficulties in motivating students, and D14, the forum is not a current tool, are related to the motivational factors that determine or influence student participation. Finally, the difficulty D17 relates to the fact that forum is not like social media; this difficulty is both structural and motivational. An attractive interface or the lack of it influences student participation. Many instructors reported that students feel unmotivated to participate in the forum because it does not look like current social media tools and websites, making forums seem like outdated tools.

The categories and difficulties that have been identified are discussed in detail below.

a) Difficulty with Forum Structure (DFS)

These are structural difficulties that relate to the structure of the forum and the lack of tools to support instructors' work or students' interaction, as mentioned by I1 and I3. "The student does not understand very well the relations of the levels of the forum; 


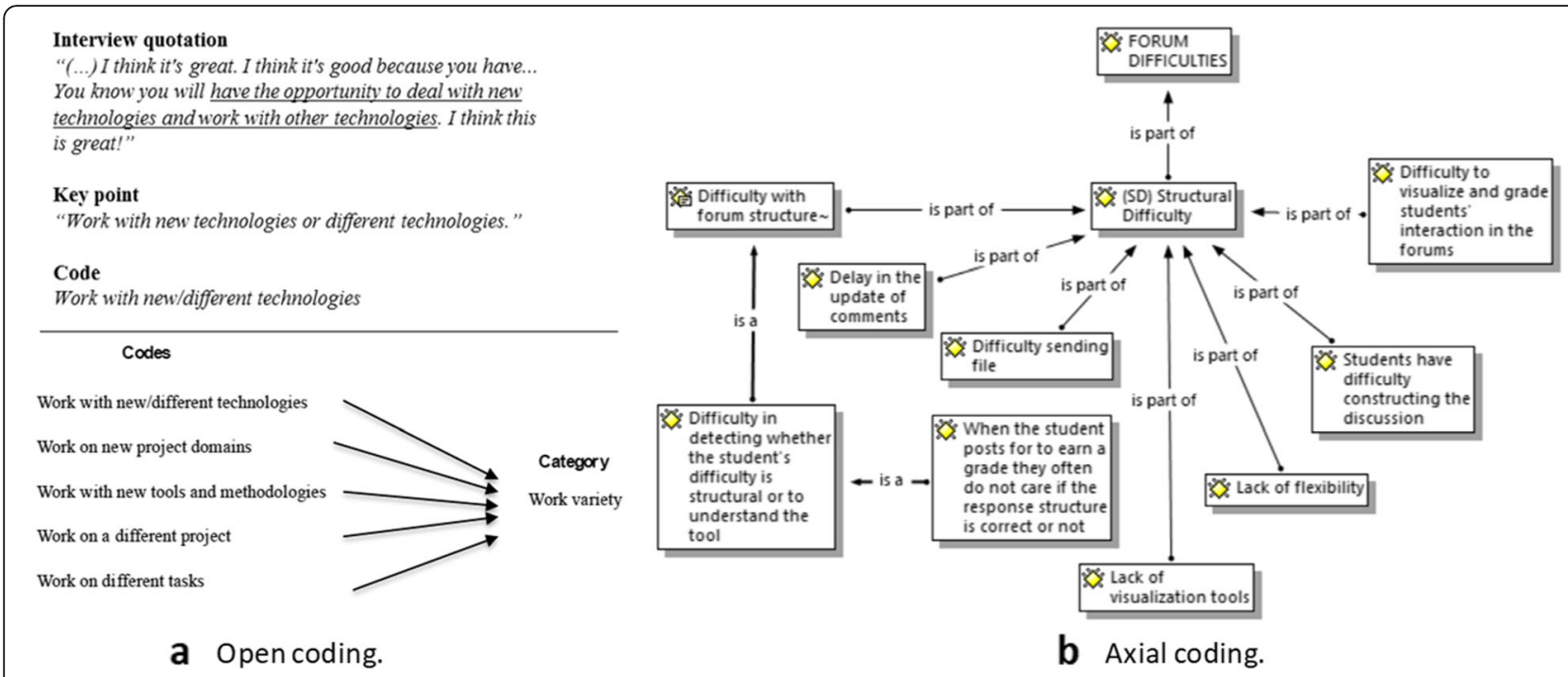

Fig. 2 The coding process. a Open coding: building codes and categories (adapted from Santos [26]). b Axial coding process of research Structural Difficulty

for example, they have difficulty knowing whom they are responding to and how they are responding in the forum" [I1].

This difficulty was also observed by Adetimirin [27], who states that many participants respond incorrectly or do not obey the structure set by the tool. According to Saramago [28], the use of a complex structure harms participation, since reading and writing become more difficult.
The forum interface also poses difficulties. "As much as we encourage, they (students) barely use the forum, they communicate by other means (WhatsApp, Facebook). I can do this discussion, but I have little feedback from the students." [I2]. The fact that the forum differs from social media interferes with student participation. "Students are accustomed to Facebook, they view the forum as a Facebook [...] students, and the instructor also misses the icons of the Facebook in the forum" [I8].

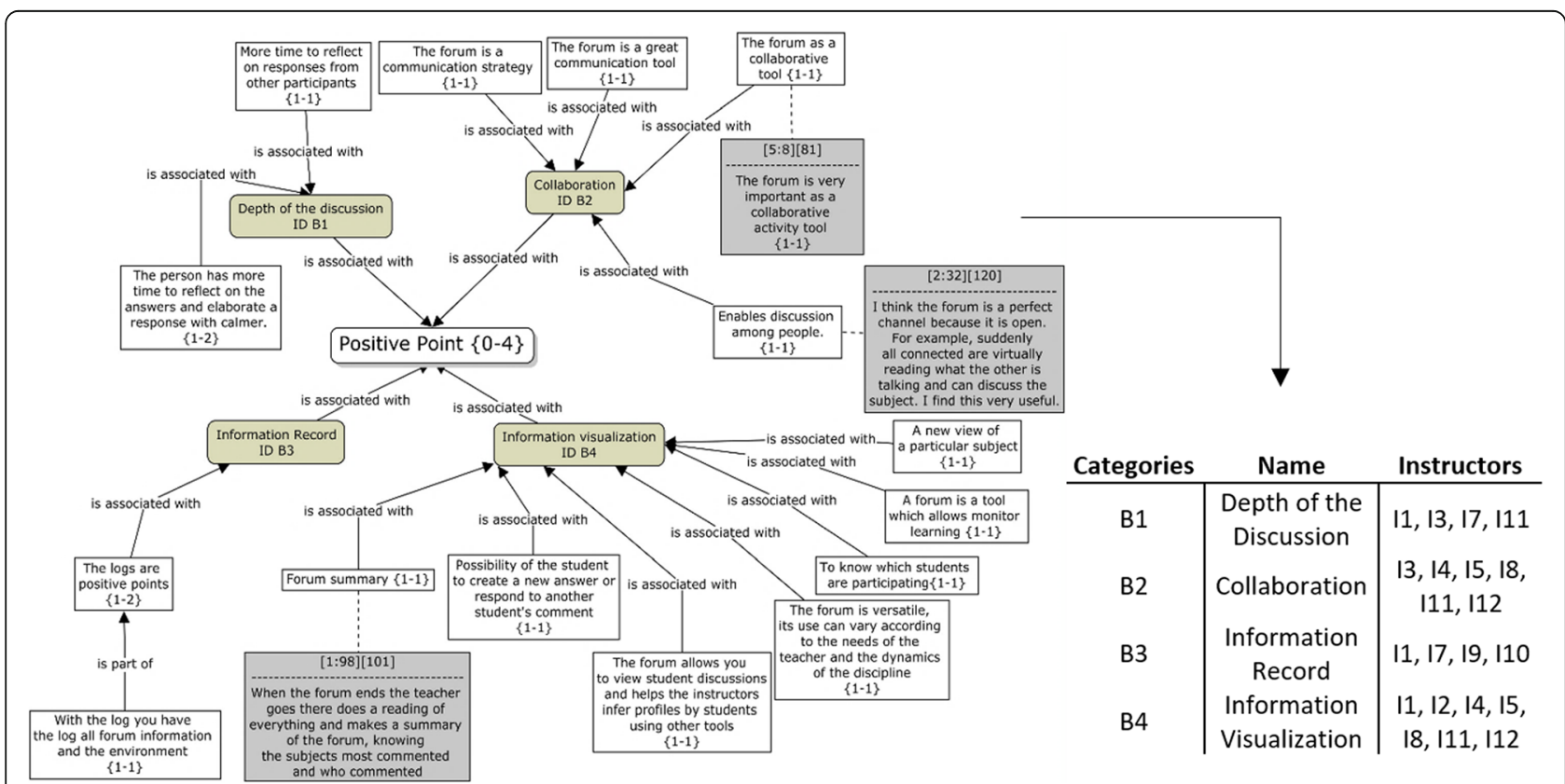

Fig. 3 Benefits Network. The figure presents the graphical representation of the benefits according to the instructors' interviews. Next to the image is a summary of the graphical representation 
Table 7 Difficulties in online discussion forums

\begin{tabular}{|c|c|c|c|}
\hline Categories & ID & Difficulties & Instructor \\
\hline \multirow[t]{5}{*}{ Accompaniment difficulty } & D1 & Difficulty in following the forum & $12,13,15,17,18$ \\
\hline & D2 & There are no resources to assist the instructors & $12,13,111,112$ \\
\hline & D3 & Difficulties to view messages & 13,16 \\
\hline & D4 & There are no stats on the forum & $13,14,19$ \\
\hline & D5 & There are no specific reports & 14,15 \\
\hline \multirow[t]{7}{*}{ Structural difficulty } & D6 & Instructors feel difficulties with forum structure & $11,12,13,18$ \\
\hline & D7 & Students have difficulty with the structure of the forum & $15,18,110$ \\
\hline & D8 & Students have difficulty constructing the discussion & 11,13 \\
\hline & D9 & Lack of visualization tools and flexibility & 11 \\
\hline & D10 & Difficulty sending file & 15 \\
\hline & D11 & Difficulties in putting students' grades & 16 \\
\hline & D12 & Delay in the update of comments & 19,110 \\
\hline \multirow[t]{4}{*}{ Motivation difficulty } & D13 & Difficulty to provide student feedback & $11,14,15$ \\
\hline & D14 & The forum is not current & $17,18,19$ \\
\hline & D15 & Students do not use the forum & $11,14,110$ \\
\hline & D16 & Lack of collaborative resource & 17,13 \\
\hline \multirow[t]{3}{*}{ Structural difficulty and Motivation difficulty } & D17 & The forum is not like social media & $17,18,19$ \\
\hline & D18 & Difficulty with forum interface & 14,110 \\
\hline & D19 & Students prefer to use social media than the forum & $17,18,112$ \\
\hline
\end{tabular}

Less experienced instructors noted difficulties in visualizing messages, as mentioned by I6. Another difficulty frequently cited by the instructors is the forum's hierarchical structure. According to I3, both he and the students have difficulties in posting their messages due to the structure of the forum: "Sometimes they (the students) do not know where to post the messages. They do not know if they must reply in the main message [...] sometimes they make improper alignments. They think they are responding to their colleague's message, but they are responding to someone else's message" [I3].

b) Lack of Incentive (LI)

Low student motivation to use the forum has been reported by many experienced instructors and is associated with the lack of features in the forum that can capture their attention. "The forum needs mediation, it needs motivation and that the instructor needs to promote the participation of the students; otherwise, student absence will predominate" [17]. "Sometimes the student just reads the question in the forum and responds, often does not check the responses of other colleagues to contribute" [I5]. Many students prefer to use social media instead. I1 reported in his interview that he participated in forums as a student, as an instructor, and currently as a coordinator and, according to him, the forum changed little and did not keep up with the current pace of asynchronous communication technology. "The biggest difficulty of the forum is that the social interaction that previously worked in the forum nowadays is in the WhatsApp groups. We have a difficulty of interaction within the educational forum. The students used to exchange messages and communicate in a forum. Nowadays it has been transformed into WhatsApp, and the distance learning platform is like a task environment" [I1].

c) Accompaniment Difficulty (AD)

Many instructors find it difficult to keep up with the discussions taking place on the forum. In general, distance education courses count on a considerable number of participants and posts, and it can be difficult for instructors to follow the comments and provide prompt feedback. In the forum, the accompaniment by instructors is important for the progress of the discussion and the participation of students.

However, instructors lack tools to assist them in monitoring and evaluating activities, as mentioned by I3 and I4: "There is no statistics to know how each one (student) participated in the discussions or to know the contributions of each one" [I3], "We don't have a forum-specific report and the forum does not provide information such as which student answered a specific question type" [I4]. 


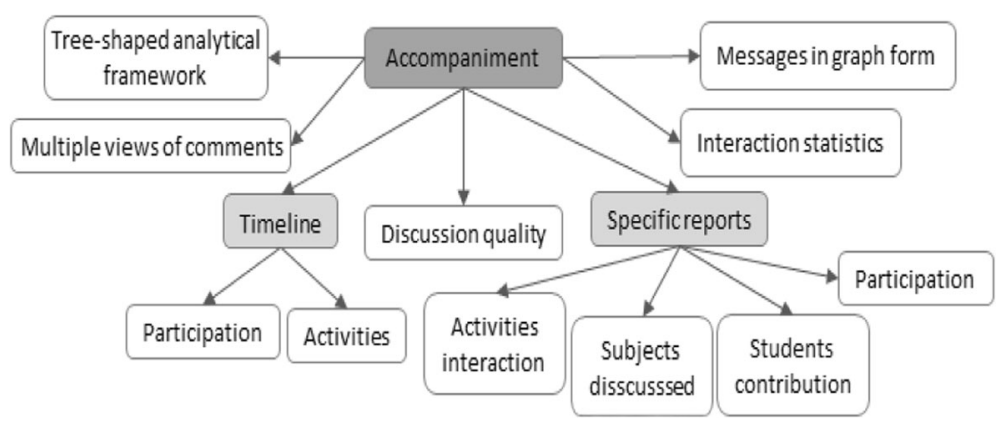

Fig. 4 Accompaniment difficulties

Curiously, less experienced instructors reported difficulties related to the lack of tools that could assist in monitoring the forum: "Some people write a lot, so I particularly could not keep up, I just kept an eye on the forum, because many people were posting. So suddenly, depending on the purpose, some people write a lot, and sometimes they are not as objective as they should be" [I2].

The structure of accompaniment difficulties is shown in Fig. 4. The figure presents the difficulties and needs that were identified in the instructors' reports, highlighting the resources that instructors lack to assist them in monitoring the activities carried out in the forum. Such resources could reduce instructors' work and improve the forum, as well as streamline instructors' evaluation and facilitate feedback for students.

The instructors report that these difficulties in following up the forum result in overload and exhausting work, as mentioned by I8: "It's a lot of work to do on the platform. I have to answer all the comments, elaborate, and evaluate the activities, promote the discussions, and intervene in the discussions [...] doing everything on my own, there is no mechanism to help" [I8].

\subsection{RQ3. What strategies do the instructors use to mediate the discussion forums?}

We identified eight strategies that can help mitigate difficulties that occur in the forum and that are related to the behavior/action of the instructors:

(S1) Logging in daily in the forum: According to the interviewees, students notice when the instructor accesses the environment. In addition, instructors need to identify the points that can generate more communication and debate, so it is important to monitor the forum. According to I3: "the instructor should look every day what is happening in the forum and comment on the students' participation. Otherwise the forum may run out of discussion or get out of context."
(S2) Follow the situation of the students: the instructor must be attentive to participation or lack of participation of the students. "It is important to see the situation of the students, whether they are following the forum and the activities. The instructor and tutor should monitor the students because if students have difficulty and they do not receive help; this discourages and can lead to dropouts" [I5].

(S3) Be objective: instructors must be objective and clearly state what they want to evaluate. According to I2 "the objective of the course and the forum has to be very explicit. From the beginning, it has to be clear to the students so that they can use the tool correctly" [12]. (S4) Check how students are accessing the course: the information in the logs can help instructors gain information about which students have accessed the courses, what information they accessed, what participants they interacted with, and which students did not interact with the other students or did not participate in the forum.

(S5) Categorize messages: This action can provide valuable information to the instructor about the students, such as the most discussed subjects and the kind of participation of each student.

(S6) Provide feedback: According to the interviewees, the students need feedback, and often instructors must foster interaction so that the students leave their comfort zone and begin to participate. "We always try to provide in the forum the mediation feedback" [I1]. (S7) Promote interaction: For the forum to be effective, it is important that students interact; thus, the instructor should encourage this exchange between students. According to I1: "we put the students to read the comments of the other students, to create a connection between them" [I1].

(S8) Creating a welcoming environment: it is fundamental to create an environment in which students become willing to participate, collaborate, and contribute with their reflections. For I5, creating an 
Table 8 Strategies vs. difficulties

\begin{tabular}{|c|c|c|c|}
\hline Strategies & Mentions & Related Difficulty & Comments \\
\hline Log in daily in the forum & $13,15,16,17$ & \multirow[t]{5}{*}{ Accompaniment } & \multirow{5}{*}{$\begin{array}{l}\text { Assists in the follow-up of the students and in obtaining the } \\
\text { information regarding the interactions and discussions. Positive } \\
\text { point: frequent monitoring will embed the instructor in the forum } \\
\text { Negative point: work overload. }\end{array}$} \\
\hline $\begin{array}{l}\text { Follow the situation of } \\
\text { the students }\end{array}$ & $11,14,15,|10| 11,, \mid 12$ & & \\
\hline Be objective & $12,15,18$ & & \\
\hline $\begin{array}{l}\text { See how students are accessing } \\
\text { the course }\end{array}$ & $11,16,19,111,112$ & & \\
\hline Categorize messages & 11,18 & & \\
\hline Provide feedback & $11,13,15,18,19,110,111,112$ & \multirow[t]{3}{*}{ Lack of incentive } & \multirow{3}{*}{$\begin{array}{l}\text { Providing feedback and creating a friendly interaction environment } \\
\text { is one of the ways to encourage and motivate students to participate } \\
\text { in the forum. Positive point: more participation in the forum. Negative } \\
\text { point: work overload. }\end{array}$} \\
\hline Promote interaction & $11,12,13,16,18,111$ & & \\
\hline $\begin{array}{l}\text { Creating a welcoming } \\
\text { environment }\end{array}$ & $12,15,18,17,111,112$ & & \\
\hline
\end{tabular}

environment in which the student feels comfortable is crucial to the discussion: "The instructor has to follow the discussion by always checking the content that the students post, however, leaving the students at ease so as not to harm the discussion" [I5].

Table 8 shows the difficulties that are related to the strategies listed above. Moreover, according to experienced instructors, when designing a distance learning discipline, it is crucial that the instructor plan and structure the virtual room before beginning the course, as well as keep in mind that it is essential to include the forum in all the units of the course to encourage student interaction with each other and discussion of the content taught.

3.4 RQ4. What improvements can be implemented in the forums according to the instructors?

Based on the reports of the instructors, we identified 5 categories of improvements that can be implemented in the forums:

I. Gamification (Gam) - according to instructors, gamification features and participation awards can encourage students to participate more in forums and activities. Motivating students within the educational environment is relevant for teaching and learning, as described by I5: "I try to use gamification, I think the imagination is everything, and you show students that they can learn by playing inside the environment." [I5].

II. Multimedia Resources (MR) - some instructors pointed out that it would be interesting to add files to the comments in the forum to complement the debate. For example, I2 suggests the integration of the forum with a specific social media to attract students to the forum. Integrating the forum with social media tools can be an effective measure as students are increasingly participating in social media and moving away from the forum.

III. Interface (In) - this category is related to improving the forum interface to make it more attractive. According to I4 "It is necessary to change the interface to give the student more desire to respond." [I4].

IV. Collaborative Resources (CR) - the instructors lack access to features of social media as pedagogical tools and they suggest, for example, including a feature that allows users to "like" a particular comment.

V. Evaluation Resources (ER) - the instructors suggest including features that assist them in evaluating the quality of the students' comments in the forum.

The identified improvements are presented in Table 9.

\section{Related work}

Our work complements the literature with qualitative data about the benefits, difficulties, strategies, and improvements for educational forums, which are currently scattered throughout the literature. In the following, we describe the related work and how it compares to our findings.

\subsection{The benefits of online discussion forums}

Several of the benefits we found in our study were also reported in the literature. According to Funaro and Montel [29], Nandi et al. [30] and Balaji [31], forums allow students and instructors to share their interests and asynchronously collaborate (B1). Discussions lead to the construction of new knowledge as individuals share learning and negotiate information through conversations [32]. In addition, Brower [33] reports that online asynchronous tools support quality discussions and 
Table 9 Forum improvements

\begin{tabular}{|c|c|c|c|}
\hline $\mathrm{ID}$ & Possible Improvements & Instructor & Category \\
\hline$\overline{\mathrm{M} 1}$ & Insert Facebook's "like" option & $11,12,18,110$ & $C R$ \\
\hline M2 & Mobile version & 11,112 & $\ln$ \\
\hline M3 & Evolution of the class through some tool & $11,13,18$ & $\ln$ \\
\hline M4 & Tool that makes forum summary available & $11,13,14,17$ & $\ln$ \\
\hline M5 & Include audios, videos & $11,15,110$ & $M R$ \\
\hline M6 & Tools to aid in follow-up & $12,13,16,17,19,110$ & ER \\
\hline M7 & Improve the template & 12,18 & $\ln$ \\
\hline M8 & Integrate WhatsApp & 12 & $C R$ \\
\hline M9 & Multiple message views & 13 & $\ln$ \\
\hline M10 & Collapse the messages and see the title of the messages before accessing & 13 & $\ln$ \\
\hline M11 & Generate reports of who interacted and did not interact & $13,14,16,18$ & EM \\
\hline M12 & Generate summary and specific reports & 14,16 & EM \\
\hline M13 & Environment adapt according to student profile & 14 & $\ln$ \\
\hline M14 & Better publish the forum & 14 & $\ln$ \\
\hline M15 & Motivation strategy & $14,15,110$ & $A G$ \\
\hline M16 & Add graphics & $13,16,17,18,110$ & EM \\
\hline M17 & Leave the forum look like a social network & 17,18 & $\ln , C R$ \\
\hline M18 & Improve flexibility, allowing the instructor more control with the tool & 110,111 & In, EM \\
\hline M19 & Integrate with tools that promote reflection and discussion & 110 & In, CR \\
\hline
\end{tabular}

collaborative learning, reaffirming the benefit of the depth of the discussion and collaboration (B2). According to Garrison et al. [34], in the forum, the time between postings led to more reflective responses than those of face-toface situations (B4). Other important benefits include flexibility, convenience, and accessibility for students to complete their learning anytime and anyplace [31].

Moreover, Balaji and Chakrabarti [31] report that online discussion forums avoid loss of data, as the students' written messages are stored in the virtual space and can be retrieved and reviewed anytime, reaffirming the importance of information records for instructors (B3). They also report that the use of online discussion forums allows students to interact more with other course participants and instructors [31].

The online discussion forums provide significant opportunities for students to actively engage in their learning process through participation [4]. The studentinstructor interaction is an essential part of the academic process [35]. Forums expand students' possibilities for exchanging ideas, with the aim of discussing topics related to the course activities [9]. According to Afify [36], the exploitation of Asynchronous Online Discussions forums offers students the possibility to teach and learn anytime and anywhere. Forums also provide students with the time needed to process learning, share ideas and points of view on e-course topics.
The literature also reports other benefits that were not mentioned by our interviews, such as the development of skills for working in virtual teams $[37,38]$ and the effects on offline (civic) engagement. According to [39], there is evidence that online engagement can translate into offline collective action.

\subsection{Difficulties in online discussion forums}

The literature also reports difficulties regarding accompaniment and structure. The forum's structure does not facilitate analyses such as monitoring students' active engagement [2]. According to Nakahara et al. [40], monitoring and classifying messages and individual participation are time-consuming tasks (c.f. D1, D2, and D3). The authors report the need to constantly oversee the environment to make calculations on the discussion data and determine whether the discussion is developing well. According to Machado et al. [41], due to the large volume of posts that are generated on a daily basis in these environments, manual analysis becomes impractical.

Mazzolini and Madison [18] showed that instructors' participation rates - including the timing of publication and the nature of their posts - affect student participation and perception. Rohfeld and Hiemstra [42] describe the instructor as the person responsible for keeping discussions on track, contributing knowledge and insights, providing discussion topics and course components, and 
maintaining group harmony. Additionally, all aspects of classroom discussion - initiation, facilitation, completion, and feedback - require different approaches in an asynchronous environment [43].

In relation to lack of incentive, Liu et al. [12] emphasize that many forums have a "poor" or lowquality interface design. Coetzee et al. [44] investigated how forum design affects student activity and learning outcomes. The findings of Thomas [4] suggest that the typical nonlinear branching structure of online discussion may be insufficient for the realization of truly conversational modes of learning.

According to Wise et al. [45], instructors and learners need to be able to find the messages that are relevant to their purposes. However, due to the considerable number of participants in MOOCs, discussion forums are often plagued by information overload and chaos [46, 47]. On top of this, a substantial proportion of MOOC posts are not directly related to the course [47]. As a result, forums become overwhelming and confusing for users to navigate [48].

From the perspective of structural and motivation difficulties, the work from Poquet and Dawson [49] report that the high number of students and the asynchronous nature of large-scale online courses make it difficult to develop a sense of belonging and didactic confidence in educational forums. The authors provide useful indicators to explore social activity in an open online course. The results of the study show that moderation in the forum is insufficient for the effective evolution of participation.

Finally, the work of Liu et al. [12] examines how participants in a MOOC interact in the course discussion forum and use social media tools to support the learning experience. The tendency to use social media is also supported by the NMC Horizon Report [50]. Their results pointed out that poor forum interface design affects students' participation and perception of utility. Some participants considered peer learning in forums useless due to poor quality or low feedback response. Other works that present difficulties in the forums are Ulrich and Nedelcu [13], Poquet and Dawson [49], Mora et al. [51], Lima et al. [52] and Bratitsis and Dimitracopoulou [53].

In our study, we identified difficulties for using educational forums that were not reported in the analyzed literature, such as the lack of statistics in the forum, lack of specific reports, lack of visualization tools, difficulty in sending files, difficulty in putting students' grades, delay in the update of comments in the forum, and lack of multimedia resources (D4, D5, D9, D10, D11, D12 and D17). Table 10 summarizes the findings in the literature and presents which difficulties were identified in this study and were not reported in the analyzed literature. In addition, the table also presents which papers propose solutions to the various categories of difficulties.

\subsection{Strategies and improvements in online discussion forums}

The literature also reports scattered strategies and improvements for educational forums. For example, Coetzee et al. [44] included a reputation system to help promote learning by giving students points for creating useful posts. According to the authors, reputation systems can result in faster response times and a higher number of responses per post, improving students' experience in the forum.

The work of Vigentini and Clayphan [54] presents strategies to motivate participants to contribute to forums, such as posing open questions. Wise et al. [45] address the overload problem in MOOC discussion forums by developing a template for automatically classifying topics. According to the authors, there are limited means to deal with overload and clutter in MOOC discussion forums. A commonly employed strategy is to define sub-forums for different purposes. Gaspar et al. [55] also propose instruments to assist instructors to classify questions posted by students on forums in order to obtain quantitative measures and to understand the types of participation.

Gerosa et al. [56] presented the use of categorization and structuring of messages in asynchronous textual communication tools. According to the authors, the message categorization supplied subsidies for the automatic classification and grouping of the messages through reports that the instructors used to understand how the discussion was progressing. Thus, the message categorization helped the reduction of the information overload for the participants, since it supplied complementary information that helped the identification of the content and structure of the discussion without read the messages.

Already the work to Filippo et al. [9] investigated the use of coordination support tools for forum mediators based on notifications presented via mobile devices in order to reduce the need for accessing the environment and monitoring the messages. The participants were informed about the forum without the need to connect to the learning environment's web interface.

Finally, the work of Alencar and Netto [57] employed intelligent agents to monitor students' activities in the discussion forums so that the students are always accompanied, and the instructor has a reduced workload. Lima et al. [58] present sociograms and tables that identify and characterize interactions among students within a Learning Management System. This strategy helped the instructors to identify the interactions of their students.

Although we have found several papers that present strategies or improvements for online discussion forums, we could not find evidence in the literature for some of the improvements suggested by our interviewees: M1, M3, M4, M5, M6, M9, M10, M12, and M18. 
Table 10 Mapping Difficulties in the interview and literature

\begin{tabular}{|c|c|c|c|c|}
\hline Categories & Difficulties & $\begin{array}{l}\text { Don't have in the } \\
\text { Literature }\end{array}$ & Difficulties references & $\begin{array}{l}\text { Improvements } \\
\text { references }\end{array}$ \\
\hline \multirow[t]{5}{*}{ Accompaniment } & \multicolumn{2}{|l|}{ Difficulty in following the forum } & {$[2,18,40,57]$} & \\
\hline & \multicolumn{2}{|l|}{ There are no resources to assist the instructors } & & {$[13,15,56,57]$} \\
\hline & \multicolumn{2}{|l|}{ Difficulties to view messages } & & \\
\hline & There are no stats on the forum & $x$ & $x$ & $x$ \\
\hline & There are no specific reports & $x$ & $x$ & $x$ \\
\hline \multirow[t]{7}{*}{ Structural } & \multicolumn{2}{|l|}{ Instructors feel difficulties with forum structure } & {$[12,16,17,41,43,44,57]$} & {$[55]$} \\
\hline & \multicolumn{2}{|l|}{$\begin{array}{l}\text { Students have difficulty with the structure of } \\
\text { the forum }\end{array}$} & & \\
\hline & $\begin{array}{l}\text { Students have difficulty constructing } \\
\text { the discussion }\end{array}$ & & & \\
\hline & Lack of visualization tools and flexibility & $x$ & $x$ & $x$ \\
\hline & Difficulty sending file (audio, video) & $x$ & $x$ & $x$ \\
\hline & Difficulties in putting students' grades & $x$ & $x$ & $x$ \\
\hline & Delay in the update of comments & $x$ & $x$ & $x$ \\
\hline \multirow[t]{4}{*}{ Motivation } & Difficulty to provide student feedback & & {$[4,11-13,16,18-20,44-48,50,52,54]$} & {$[14,44,54]$} \\
\hline & Students do not use the forum & & & \\
\hline & Lack of collaborative resource & & & \\
\hline & \multicolumn{2}{|l|}{ The forum is not current } & & \\
\hline \multirow{4}{*}{$\begin{array}{l}\text { Structural and } \\
\text { Motivation }\end{array}$} & \multicolumn{2}{|l|}{ Difficulty with forum interface } & {$[12,16,49,50]$} & $x$ \\
\hline & \multicolumn{2}{|l|}{$\begin{array}{l}\text { Students prefer to use social media } \\
\text { than the forum }\end{array}$} & & $x$ \\
\hline & $\begin{array}{l}\text { The forum is not like } \\
\text { social media }\end{array}$ & $x$ & $x$ & $x$ \\
\hline & Integrate with WhatsApp & $x$ & $x$ & $x$ \\
\hline
\end{tabular}

\subsection{Relation between the research findings and existing solutions}

We identified some publications that carry out investigations aiming to strengthen forums or promote social interaction among the participants. These publications present different results such as systems, frameworks, and plugins for the forums.

For Machado et al. [41], the analysis of students' interactions in the forum tool can identify learning difficulties. However, due to the large number of messages that are created, a manual analysis of students' posts can become a very time-consuming task. Their work presents a computational model that seeks to evaluate the thematic relevance of the posts made by students. The authors developed a pedagogical support tool to allow early identification of students with learning difficulties, as well as students who have made relevant contributions on the topic of the discussion. The difficulties presented by Machado [41] relate to difficulties D1 and D3 and the solution relates to the improvements M6 and M18 presented by our work.

$\mathrm{Hu}$ et al. [59] propose a framework named Concept Map of Forum (CMF) to analyze online discussion forums in Moodle. The framework analyzes interaction and contents based on students' interaction with peers and posts. In traditional classroom, instructors can observe the students' learning process and adjust teaching strategies. However, it is difficult for instructors to understand how students learn in online forums. The difficulties presented by $\mathrm{Hu}$ [59] relate to difficulties D1, D2, and D3, and the solution was not identified in our work.

Moreno-Marcos [60] propose a novel methodology, named 3S (Social, Sentiments, Skills), for analyzing forum interactions in MOOCs and a visual analytics tool for the analysis of forum activity according to the proposed methodology. The 3S methodology supports instructors in understanding learners' behaviors such as the increase of activity near critical dates. Instructors can also benefit by increasing their awareness of difficulties to acquire certain skills, which may lead to redesign of some parts of the course. According to the authors, the $3 \mathrm{~S}$ methodology should be adapted to each course, regardless of the platform. The difficulties presented by work [60] relate to difficulty D2 and the proposed solution was not identified our work.

Other works also propose improvements to the forum in the form of framework, tools, or plugins: such as [49, $58,61]$. The works focus on similar difficulties D2, D6, 
D7, D13, D17 and propose improvements that relate to M3, M4, M6, M11, and M13.

In addition, regarding the possibility of instructors to be able to evaluate the quality of the students' comments in the forum, we can complementary that these characteristics already exist in forums of social platforms, where the users comments are rated by the community according to their quality and adherence to the questions proposed, such as Quora and Stack Overflow forums.

\section{Implications}

In this section, we discuss the implications of this study for research and practice from the point of view of different stakeholders.

LMS Forums vendors - our work has identified several issues related to the design of distance learning forums. Although the LMS Moodle is predominant among our interviews, the results may be applied to other LMS that has a similar design. We also present strategies that instructors use and that are not necessarily supported by specific forums, as can be observed in Section 4.

Instructors/Teachers - our work provides instructors with a list of 8 strategies they can adopt in their classes, such as frequent follow-up, student feedback, and more (Section 3.3). The strategies identified are intended to assist instructors with actions they can take within the course so that the forum moves smoothly, and students participate in discussions. In addition, the strategies presented in this paper may assist newcomer instructors who have no Distance Learning Course experience and often do not receive training to handle this. According to I11: "It is not easy to be a distance learning teacher, most teachers come from face-to-face teaching and do not know how to present a communication that is easy for the student to understand, this and other skills are important for a teacher who teaches in the classroom distance".

Coordinators of educational platforms - our work has identified and presented 19 difficulties related to online discussion forums. These difficulties can be explored by and help platform coordinators develop ways to leverage distance learning environments. In addition, we provide a set of strategies that can assist distance learning instructors, monitors, and coordinators. Therefore, the coordinators of educational platforms can make use of our findings to develop and deliver materials to support instructors. They can also make use of our findings to better understand the difficulties faced by instructors of online discussion forums. The instructors reported that many students turn to social media platforms to discuss course subjects. Therefore, it is important to offer new possibilities of interaction and support to instructors and students; otherwise, the forum will be less used, and instructors will continue to face difficulties understanding the participation of their students in the forum. The evidence presented here serves as a starting point for the adoption of measures aimed at improving forums and making them a more usual tool.

Informatics in Education/Distance Learning Community - we noticed that many instructors do not receive adequate training and do not have adequate online support. According to the interviews, the difficulties hinder the feedback and understanding of the discussion. In this way, the distance learning community could prepare tutorials, adequate support, and training for people working in distance learning. After all, a well-developed discussion forum in an e-learning course can create an active, interactive, and participatory learning environment [62]. Also, Moodle distance learning communities can use our findings to promote improvements in the Moodle LMS, that are used by the instructors who participated in our interviews. Table 9 presents several suggested improvements. Our work has cataloged 19 difficulties and 19 improvements that can be implemented in the forums or investigated in more detail.

Researchers - our work has identified several benefits, difficulties, strategies, and improvements for educational forums. As can be seen in Table 7, there are many open gaps in relation to the difficulties faced by instructors, which can be explored in future research. Still, we present improvements related to the difficulties. This information can be explored and used to empower forums, given that this teaching tool needs to be adapted to meet the needs of the new generation. More research is also needed to investigate how to overcome the difficulties, to evaluate the effectiveness of the strategies in different contexts, and to implement the suggested improvements to the forums. It would be also of great interest to analyze and understand the motivating and demotivating factors that influence students.

\section{Limitations}

The results obtained in this study are exploratory. To obtain a full comprehension of the phenomenon as a whole, more collection and analysis cycles and participants from different fields and regions are necessary. However, our results list recurrent benefits, difficulties, strategies, and suggestions from the point of view of experienced instructors, which can be useful for novice instructors, LMS vendors, course designers, and researchers.

Additionally, we acknowledge that we likely did not identify all possible benefits, difficulties, strategies, and improvements. We are aware that the universe of online discussion forums is enormous, which means that the findings may differ according to the platform used and cultural context. Our strategy of considering different instructor profiles and institutions aimed to alleviate this 
problem. However, as all interviewees adopt Moodle, the results may be only generalizable to contexts similar to the one mentioned above.

Another limitation is the subjectivity of data classification. We applied Grounded Theory procedures to mitigate this issue. All analysis was grounded on the collected data and we carefully followed systematic means to conduct the analysis.

Our study was conducted with instructors from public institutions and most of them teach informatics/computer science courses. We also considered participants from other disciplines who had several years of experience with distance learning platforms (at least 5 years). After performing the analysis of the first 10 interviews, we conduct two additional interviews with instructors from courses not related to computer science. These new interviews did not reveal much new information.

Finally, another limitation of this study is the generalization of our results to all distance education instructors. Our study intends to allow analytical generalization, enabling the results to extend to contexts/cases with common characteristics and for which the results are relevant.

\section{Conclusion and future work}

In this work, we identify and catalog: benefits that forums present within the context of distance learning; difficulties instructors face in using educational forums; strategies that instructors can adopt to mitigate these difficulties; and improvements that can be implemented to generate forums that meet the needs of both instructors and students. We collected data from the point of view of instructors who teach distance education classes.

The empirical study revealed three categories of difficulties related to the forum: difficulties in following the debate, difficulties with the structure of the forum, and difficulties in motivating students. The study also allowed the identification of eight strategies that are related to the behavior/action of the instructors and five categories of improvements that can be implemented in the forums.

The results presented in this paper are relevant for understanding of the instructors' perspective, serving as support for researchers, developers, instructors, and communities of distance learning. In addition, our results can offer insights for research to promote and facilitate the use of forums.

As a future work, we plan to conduct a more comprehensive investigation and test some of the improvements to understand the extent to which our results apply and also to discover new factors that affect the interaction and use of educational discussion forums. For this, we intend to conduct a survey that will provide more information and help in understanding the phenomenon as a whole, collecting the opinion of a higher number of participants. We also intend to conduct more data analysis collection cycles through new rounds of interviews with instructors from other regions and disciplines.

\section{Supplementary information}

Supplementary information accompanies this paper at https://doi.org/10. 1186/s13174-019-0120-0.

Additional file 1. Graphical representation with the associations related to the benefits.

Additional file 2. Graphical representation with the associations related to the difficulties.

Additional file 3. Graphical representation with the associations related to the improvements.

Additional file 4. Mapping between benefits, difficulties, strategies, and improvements.

\section{Abbreviations}

AG: Gamification; CMF: Concept map of forum; CR: Collaborative resources; DFS: Difficulty with forum structure; DI: Instructor difficulties; ER: Evaluation resources; GT: Grounded-Theory; In: Interface; LMS: Learning Management System; MOOC: Massive Open Online Course; MR: Multimedia resource

\section{Acknowledgements}

We would like to thank the people who agreed to participate in the interviews and take the time to answer our questions and share their experiences in the online educational forums. We thank CAPES for the financial support granted to the work, the FAPEAM, and the two involved universities: UFAM and NAU.

\section{Authors' contributions}

DPRL is PhD student at IComp-UFAM, conducted the overall data collection and analysis and worked on most of the manuscript. MAG is the co-advisor for DPRL and helped direct the work, participated in the analysis, writing of the manuscript and in its successive revisions. TUC participated in the data collection and analysis and in the manuscript review. JFMN is the advisor for DPRL and participated in the data collection and research design. All authors read and approved the final manuscript.

\section{Funding}

This research partially funded by DS/CAPES 2015 and FAPEAM through edital 009/2017. Tayana Conte thanks the financial support granted by CNPq through process number 311494/2017-0.

\section{Availability of data and materials}

The datasets used and/or analyzed during the current study are available from the corresponding author on reasonable request. The Graphical representation elaborate and used in the analyze this paper are available at https://docs.google.com/document/d/1aqmGgeUa8GL_K637mDGcP3 xGJFdbOzEGvKTImepjP_l/edit?usp=sharing

Competing interests

The authors declare that they have no competing interests.

\section{Author details}

${ }^{1}$ Federal University of Amazonas - UFAM, Manaus, Brazil. ${ }^{2}$ Northern Arizona University - NAU, Flagstaff, USA.

Received: 4 July 2019 Accepted: 17 October 2019

Published online: 04 December 2019

References

1. Wise AF, Marbouti F, Hsiao Y, Hausknecht S. A survey of factors contributing to learners 'listening' behaviors in asynchronous online discussions. J Educ Comput Res. 2012;47(4):461-80. https://doi.org/10.2190/EC.47.4.F. 
2. Bakharia A, Dawson S. SNAPP: a bird's-eye view of temporal participant interaction. In: Proceedings of the 1st international conference on learning analytics and knowledge; 2011. p. 168-73. https://doi.org/10.1145/2090116. 2090144.

3. Koutropoulos A, Gallagher MS, Abajiam S, Ward I, Hogue R, Keskin N, Rodriguesz C. Emotive vocabulary in MOOCs: Context \& Participant Retention. Eur J Open, Distance E-Learning. 2012:1-23. https://files.eric.ed. gov/fulltext/EJ979609.pdf.

4. Thomas M. Learning within incoherent structures: the space of online discussion forums. J Comput Assist Learn. 2002;18(3):351-66. https://doi.org/ 10.1046/j.0266-4909.2002.03800.X.

5. Jiang Z, Zhang Y, Liu C, Li X. Influence analysis by heterogeneous network in MOOC forums: what can we discover? Int Educ Data Min Soc. 2015:242249. https://files.eric.ed.gov/fulltext/ED560574.pdf.

6. Stephens-Martinez K, Hearst MA, Fox A. Monitoring moocs: which information sources do instructors value? In: Proceedings of the first ACM conference on Learning@ scale conference; 2014. p. 79-88. https://doi.org/ 10.1145/2556325.2566246.

7. Gillbert PK, Dabbagh N. How to structure online discussions for meaningful discourse: a case study. Br J Educ Technol. 2005;36(1):5-18. https://doi.org/ 10.1111/j.1467-8535.2005.00434.x.

8. Benbunan-Fich R, Hiltz SR. Impacts of asynchronous learning networks on individual and group problem solving: a field experiment. Gr Decis Negot. 1999;8(5):409-26. https://doi.org/10.1023/A:1008669710763.

9. Filippo D, Fuks H, de Lucena CJP. Discussion forum coordination support in distance courses. Scie Interdiscip Stud Comput Sci 2009. 2009;20(1):25-40. https://doi.org/10.4013/sct.2009.20.1.03.

10. Abawajy J, Kim T. Online learning environment: taxonomy of asynchronous online discussion forums. In: International Conference on Advanced Software Engineering and Its Applications; 2011. p. 706-14. https://doi.org/ 10.1007/978-3-642-27207-3_76.

11. Watson A. Developing teaching practice for more effective use of synchronous discussion: a preliminary investigation, Proceedings Ascilite Melbourne; 2008. p. 1090-9.

12. Liu M, Kang J, McKelroy E, Harron J, Liu S. Investigating students' interactions with discussion forums, Facebook, and twitter in a MOOC and their perceptions. In: Revolutionizing Modern Education through Meaningful E-Learning Implementation, IGI Global; 2016. p. 18-41. https://doi.org/10. 4018/978-1-5225-0466-5.ch002.

13. Ulrich C, Nedelcu A. Moocs in our university: hopes and worries. ProcediaSocial Behav Sci. 2015;180:1541-7. https://doi.org/10.1016/j.sbspro.2015.02.304.

14. Gerosa M, Filippo D, Pimentel M, Fuks H, Lucena C. Is the unfolding of the group discussion off-pattern? Improving coordination support in educational forums using mobile devices. Comput Educ. 2010;54(2):528-44. https://doi.org/10.1016/j.compedu.2009.09.004

15. de Faria E, Yamanaka K, Tavares J, Pinto G, de Melo L. Intelligent software agents mediating the pair participation in a distributed intelligent pairsoftware development environment, in 2008 32nd Annual IEEE International Computer Software and Applications Conference; 2008. p. 517-20. https:// doi.org/10.1109/COMPSAC.2008.177.

16. Sayfouri N. Evaluation of the learning management system using students' perceptions. Med J Islam Repub Iran. 2016;30:460 Available via https:/www. ncbi.nlm.nih.gov /pmc/articles/PMC5419244/.

17. Xu B, Yang D. Study partners recommendation for $\mathrm{xMOOCs}$ learners. Comput Intell Neurosci. 2015;2015:15. https://doi.org/10.1155/2015/ 832093.

18. Mazzolini M, Maddison S. When to jump in: the role of the instructor in online discussion forums. Comput Educ. 2007;49(2):193-213. https://doi.org/ 10.1016/..compedu.2005.06.011.

19. Spencer D, Hiltz S. A field study of use of synchronous chat in online courses. In: 36th Annual Hawaii International Conference on System Sciences, 2003. Proceedings of the; 2003. p. 10. https://doi.org/10.1109/ HICSS.2003.1173742.

20. Höver K, Mühlhäuser M. Evaluating a linked open online course. In: 2014 IEEE International Symposium on Multimedia; 2014. p. 375-80.

21. Glaser B, Strauss L. Discovery of grounded theory: strategies for qualitative research. New York: Routledge; 2017.https://doi.org/10.4324/ 9780203793206

22. Runeson P, Host M, Rainer A, Regnell B. Case study research in software engineering: quidelines and examples. New Jersey: Wiley; 2012. http://www. egov.ee/media/1267/case-study-research-in-software-engineering.pdf.
23. Bandeira-De-Mello R, Garreau L. How to develop creativity in grounded theory? Epistemological choices and operational strategies in the quest for creativity. In: Proc. Int. Strateg. Manag. Assoc. (AIMS), Grenoble, Fr; 2009.

24. Pozzebon M, Petrini M, de Mello RB, Garreau L. Unpacking researchers' creativity and imagination in grounded theorizing: an exemplar from IS research. Inf Organ. 2011;21(4):177-93. https://doi.org/10.1016/j.infoandorg. 2011.09.001.

25. Strauss A, Corbin J. Basics of qualitative research: techniques and procedures for developing grounded theory 1998; 2". Thousand Oaks: CASage Publications; 1982.

26. Glaser B. "Theoretical sensitivity", Adv. Methodol. grounded theory; 1978.

27. Adetimirin A. An empirical study of online discussion forums by library and information science postgraduate students using technology acceptance model 3. J Inf Technol Educ Res. 2015;14(1):257-69 Available via http:// www.jite.org/documents/Nol14/JTEv14ResearchP257-269Adetimirin1854.pdf.

28. Saramago F. Representations for computational modeling of network structured discussion: representations for computational modeling of networked discussion (in Portuguese). Dissertation, Pontifical Catholic University of Rio de Janeiro; 2007.

29. Funaro G, Montell F. Pedagogical roles and implementation guidelines for online communication tools. ALN Mag. 1999;3(2):1-9.

30. Nandi $\mathrm{D}$, Hamilton $\mathrm{M}$, Harland J. Evaluating the quality of interaction in asynchronous discussion forums in fully online courses. Distance Educ. 2012; 33(1):5-30.

31. Balaji MS, Chakrabarti D. Student interactions in online discussion forum: empirical research from'media richness theory'perspective. J Interact online Learn. 2010;9(1):1-22. https://www.ncolr.org/jiol/issues/pdf/9.1.1.pdf.

32. Katz S, Connelly J, Wilson C. When should dialogues in a Scaffolded learning system take place? In: EdMedia+ Innovate Learning; 2005. p. 2850-5.

33. Brower $\mathrm{H}$. On emulating classroom discussion in a distance-delivered OBHR course: creating an on-line learning community. Acad Manag Learn Educ. 2003;2(1):22-36. https://doi.org/10.5465/amle.2003.9324013.

34. Garrison DR, Anderson T, Archer W. Critical inquiry in a text-based environment: computer conferencing in higher education. Internet High Educ. 1999;2(2-3):87-105.

35. Anderson T. Towards a theory of online learning. In: Theory Practice online Learn (2ed), vol. 2; 2004. p. 109-19.

36. Afify MK. The influence of group size in the asynchronous online discussions on the development of critical thinking skills, and on improving students' performance in online discussion forum. Int J Emerg Technol Learn. 2019;14(5):132-52.

37. Palmer S, Holt D, Bray S. Does the discussion help? The impact of a formally assessed online discussion on final student results. Br J Educ Technol. 2008; 39(5):847-58. https://doi.org/10.2190/EC.47.4.f.

38. Conaway R, Easton $S$, Schmidt W. Strategies for enhancing student interaction and immediacy in online courses. Bus Commun Q. 2005;68(1): 23-35. https://doi.org/10.1177/1080569904273300.

39. Pendry L, Salvatore J. Individual and social benefits of online discussion forums. Comput Human Behav. 2015;50:211-20. https://doi.org/10.1016/j. chb.2015.03.067.

40. Nakahara J, Hisamatsu S, Yaegashi K, Yamauchi Y. iTree: does the mobile phone encourage learners to be more involved in collaborative learning? In: Proceedings of th 2005 conference on Computer support for collaborative learning: learning 2005: the next 10 years! 2005. p. 470-8.

41. MacHado C, Maclel A, Rodrigues R, Menezes R. An approach for thematic relevance analysis applied to textual contributions in discussion forums. Int J Distance Educ Technol. 2019;17(3):37-51. https://doi.org/10.4018/ijdet2019. 070103.

42. Rohfeld R, Hiemstra R. Moderating discussions in the electronic classroom; 1995.

43. Dennen VP. From message posting to learning dialogues: factors affecting learner participation in asynchronous discussion. Distance Educ. 2005;26(1): 127-48. https://doi.org/10.1080/01587910500081376.

44. Coetzee D, Fox A, Hearst MA, Hartmann B. Should your MOOC forum use a reputation system? In: Proceedings of the 17 th ACM conference on Computer supported cooperative work \& social computing; 2014. p. 117687. https://doi.org/10.1145/2531602.2531657.

45. Wise AF, Cui Y, Vytasek J. Bringing order to chaos in MOOC discussion forums with content-related thread identification. In: Proceedings of the Sixth International Conference on Learning Analytics \& Knowledge; 2016. p. 188-97. 
46. McGuire R. Building a sense of community in MOOCs. Campus Technol. 2013;26(12):31-3.

47. Brinton C, Chiang M, Jain S, Lam H, Liu Z, Wong F. Learning about social learning in MOOCs: from statistical analysis to generative model. IEEE Trans Learn Technol. 2014;7(4):346-59. https://doi.org/10.1109/TLT.2014.2337900.

48. Hollands F, Tirthali D (2014) MOOCs: expectations and reality, Full report. NY Cent. Benefit Cost Stud. Educ. Teach. Coll. Columbia Univ.

49. Poquet O, Dawson S, Dowell N. How effective is your facilitation?: grouplevel analytics of MOOC forums. In: Proceedings of the Seventh International Learning Analytics \& Knowledge Conference; 2017. p. 208-17. https://doi.org/10.1145/3027385.3027404.

50. Johnson L, Becker S, Estrada V, Freeman A (2014) NMC horizon report: 2014 K. The New Media Consortium.

51. Mora N, Caballe S, Daradoumis T. Providing a multi-fold assessment framework to virtualized collaborative learning in support for engineering education. Int J Emerg Technol Learn. 2016;11(7):41-51.

52. Lima D, Gerosa M, Netto JF. Using awareness information to enhance online discussion forums: a systematic mapping study. In: 2018 IEEE Frontiers in Education Conference (FIE); 2018. p. 1-9. https://doi.org/10.1109/FIE.2018. 8658487.

53. Bratitsis T, Dimitracopoulou A. Interaction analysis as a multi-support approach of social computing for learning, in the 'collaborative era': lessons learned by using the DIAS system. In: 2008 Eighth IEEE International Conference on Advanced Learning Technologies; 2008. p. 536-8. https://doi. org/10.1109/ICALT.2008.260.

54. Vigentini L, Clayphan A. Exploring the function of discussion forums in MOOCs: comparing data mining and graph-based approaches. In: EDM (Workshops); 2015

55. Gaspar A, Langevin S, Boyer N, Armitage W. Students' Activity Focus in Online Asynchronous Peer Learning Forums. Inform Educ. 2010;9(1):19-36.

56. Gerosa MA, Fuks H, Lucena CJP. Use of categorization and structuring of messages in order to organize the discussion and reduce information overload in asynchronous textual communication tools. In: Proc- 7th Int Work. Groupware, CRIWG 2001; 2001. p. 136-41.

57. Alencar M, Netto JF. Improving cooperation in Virtual Learning Environments using multi-agent systems and AIML. In: 2011 Frontiers in Education Conference (FIE); 2011. p. F4C-1. https://doi.org/10.1109/FIE.2011. 6143025.

58. Lima D, Netto JF, Bremgartner V. Applying social network analysis in a course supported by a LMS: report of a case study. In: 2017 IEEE Frontiers in Education Conference (FIE); 2017. p. 1-9. https://doi.org/10.1109/FIE.2017. 8190485.

59. Hu Q, Huang Y, Deng L. A method for analysis of online discussion forum in moodle. In: 13th Int. Conf. Comput. Sci. Educ. ICCSE 2018, no Iccse; 2018. p. 548-51. https://doi.org/10.1109/ICCSE.2018.8468733.

60. Moreno-Marcos PM, Alario-Hoyos C, Munoz-Merino PJ, Estevez-Ayres I, Kloos CD. A learning analytics methodology for understanding social interactions in MOOCs. IEEE Trans Learn Technol. 2018, 2018. https://doi.org/10.1109/TLT. 2018.2883419

61. Delium C. OSCAR: a framework for structuring mediated communication by speech acts, in proceedings 3rd IEEE international conference on advanced technologies, 229-233. 2003. https://doi.org/10.1109/ICALT.2003.1215062.

62. Khan BH (2005) Managing e-learning: design, delivery, implementation, and evaluation. IGI Global.

\section{Publisher's Note}

Springer Nature remains neutral with regard to jurisdictional claims in published maps and institutional affiliations.

\section{Submit your manuscript to a SpringerOpen ${ }^{\circ}$ journal and benefit from:}

- Convenient online submission

- Rigorous peer review

- Open access: articles freely available online

- High visibility within the field

- Retaining the copyright to your article

Submit your next manuscript at $\boldsymbol{\nabla}$ springeropen.com 